\title{
Cardiorespiratory parameters during submaximal exercise under acute exposure to normobaric and hypobaric hypoxia
}

\author{
Carla Basualto-Alarcón ${ }^{a}$, Gil Rodas ${ }^{b}$, Pedro A. Galilea ${ }^{c}$, Joan Riera ${ }^{c}$, \\ Teresa Pagés ${ }^{d}$, Antoni Ricart ${ }^{e}$, Joan R. Torrella ${ }^{d}$, Claus Behn ${ }^{a}$, Ginés Viscor ${ }^{d, *}$ \\ a Laboratorio de Ambientes Extremos (ICBM), Facultad de Medicina, Universidad de Chile, Santiago de Chile, Chile \\ b Serveis Mèdics, Futbol Club Barcelona, Barcelona, Spain \\ ' GIRSANE, Centre d'Alt Rendiment Esportiu (CAR), Sant Cugat del Vallès, Barcelona, Spain \\ d Departament de Fisiologia i Immunologia, Universitat de Barcelona, Barcelona, Spain \\ e Hospital Universitari de Bellvitge, L'Hospitalet de Llobregat, Barcelona, Spain
}

Received 23 August 2011; accepted 23 November 2011

Available online 11 January 2012

\author{
KEYWORDS \\ Heart rate variability; \\ Hypoxia tolerance; \\ Hypoxic tent; \\ Hypobaric chamber; \\ Arterial oxygen \\ saturation
}

\begin{abstract}
Seven healthy young men were submitted twice to a hypoxia tolerance test at a simulated altitude $(3000 \mathrm{~m})$. Their first acute exposure was in a hypobaric chamber; and the second, in a hypoxic tent. Cardiorespiratory parameters and heart rate variability measurements were obtained under each hypoxic condition. A significant decrease of $6 \%$ to $8 \%$ compared to normal oxygen conditions was observed in arterial oxygen saturation $\left(\mathrm{SpO}_{2}\right)$ in both hypoxic conditions at rest; whereas exercise led to decreases of $10 \%$ in $\mathrm{SpO}_{2}$ despite an increase of $27 \%$ in respiratory minute volume. The low frequency (LF) and high frequency (HF) components of heart rate variability significantly changed from normoxia (LF: 37.1, HF: 62.9, LF/HF: 1.27) to hypobaric hypoxia (HH) (LF: 49.1, HF: 50.6, LF/HF: 1.96). However, these changes were not observed under normobaric hypoxia. Thus, heart rate variability behaved differently in the two hypoxic conditions, supporting the hypothesis that normobaric hypoxia and hypobaric hypoxia are not equal stimuli to the cardiovascular and respiratory systems. A correlation was found between sympathetic and vagal modulations in normoxia and $\mathrm{SpO}_{2}$ at exercise under hypobaric hypoxia $(\mathrm{HH})$. Individuals with higher sympathetic modulation ( $\mathrm{LF} \%)$ in normoxia had higher $\mathrm{SpO}_{2}$ at exercise under $\mathrm{HH}(r=0.808, P<0.05)$ and individuals with higher vagal modulation $(\mathrm{HF} \%)$ in normoxia showed a trend to lower $\mathrm{SpO}_{2}$ in exercise under $\mathrm{HH}(r=-0.636, P=0.125)$. This opens up the possibility of using this correlation as a tool for predicting the individual capacity to altitude acclimatization.

(C) 2011 Consell Català de l'Esport. Generalitat de Catalunya. Published by Elsevier España, S.L. All rights reserved.
\end{abstract}

\footnotetext{
* Corresponding author.

E-mail address: gviscor@ub.edu (G. Viscor).
} 


\section{PALABRAS CLAVE}

Variabilidad de la frecuencia cardiaca; Prueba de tolerancia a hipoxia;

Tienda hipóxica; Cámara hipobárica; Saturación arterial de oxígeno

\section{Parámetros cardiorrespiratorios durante ejercicio submáximo en hipoxia aguda hipobárica y normobárica}

\begin{abstract}
Resumen Siete jóvenes sanos y en buena condición física realizaron dos pruebas de tolerancia a hipoxia a una altitud simulada de $3.000 \mathrm{~m}$. La primera fue en cámara hipobárica, mientras que la segunda se efectuó en una tienda hipóxica. Se registraron varios parámetros cardiorrespiratorios y la variabilidad de la frecuencia cardiaca. En comparación con las condiciones de normoxia, se observó un decremento significativo del $6 \%$ al $8 \%$ en la saturación de oxígeno arterial $\left(\mathrm{SpO}_{2}\right)$ en reposo en ambas condiciones de hipoxia. El ejercicio desencadenó descensos de un $10 \%$ en $\mathrm{SpO}_{2}$ pese a un incremento del $27 \%$ del volumen minuto ventilatorio. Tanto los componentes de baja (LF) como alta frecuencia (HF) de la variabilidad del ritmo cardiaco cambiaron significativamente en hipoxia hipobárica (LF: 49,1, HF: 50,6, LF/HF: 1,96) respecto a normoxia (LF: 37,1, HF: 62,9, LF/HF: 1,27). Estos cambios no se apreciaron en condiciones de hipoxia normobárica, lo cual apoya la hipótesis de que la hipoxia hipobárica y normobárica no suponen igual estímulo para los sistemas respiratorio y cardiovascular. Se ha observado una correlación entre la modulación vagal y simpática en normoxia y la $\mathrm{SpO}_{2}$ durante ejercicio en cámara hipobárica. Los sujetos con mayor modulación simpática (LF\%) en normoxia presentan mayor $\mathrm{SpO}_{2}$ en ejercicio en la cámara $(\mathrm{r}=0,808, \mathrm{p}<0,05)$ y los individuos con mayor modulación vagal ( $\mathrm{HF} \%)$ en normoxia tienden a $\mathrm{SpO}_{2}$ más bajas en ejercicio en hipobaria $(r=-0,636$, $p=0,125$ ). Surge la posibilidad de utilizar esta asociación como herramienta predictiva de la capacidad individual de aclimatación a la altura.

(c) 2011 Consell Català de l'Esport. Generalitat de Catalunya. Publicado por Elsevier España, S.L. Todos los derechos reservados.
\end{abstract}

\section{Introduction}

In newcomers to high altitude, aerobic work capacity appears to be diminished. ${ }^{1-4}$ Individual aerobic work capacity is usually calculated by determining the maximal oxygen consumption rate $\left(\mathrm{VO}_{2} \mathrm{max}\right)$. This parameter assesses general oxygen availability at the cell level, including oxygen diffusion and transport, and the mitochondrial processes that take place in the organism. During hypobaric hypoxia, $\mathrm{VO}_{2}$ max falls and this reduction is not wholly reversed even after restoration of oxygen uptake. ${ }^{5}$ As a response to the partial pressure reduction of oxygen at alveolar level, there are certain changes in other physiological parameters in order to maintain oxygen uptake to the tissues. Characteristic changes elicited by altitude, as a consequence of the lower arterial $\mathrm{pO}_{2}$, are hyperventilation, resulting in respiratory alkalosis, ${ }^{6}$ and increases in heart rate and arterial blood pressure. ${ }^{7}$ One of the changes observed in relation to hypoxia is an increase in oxidative stress damage. ${ }^{8}$ It has been suggested that this phenomenon is due, at least in part, to recurrent conditions of ischemia-reperfusion, which could cause cell damage and induce signaling for apoptotic pathways. ${ }^{9}$

In addition, changes in autonomous nervous system (ANS) activity at moderate and high altitude have been evaluated by recording heart rate variability (HRV). This noninvasive electrocardiographic marker reflects the activity of the sympathetic and vagal components of the ANS. It expresses the total amount of variations of RR intervals (intervals between QRS complexes of normal sinus depolarization). ${ }^{10}$ HRV analysis is widely used in exercise medicine, with a significant correlation between HRV and $\mathrm{VO}_{2}$ max reported in athletes, ${ }^{11}$ and increased HRV indices have also been found in highly trained cyclists. ${ }^{12}$
Preliminary studies measuring HRV during acute hypobaric hypoxia exposure reported a reduction in HRV by means of a decrease in total spectral power. ${ }^{13,14}$ These studies demonstrated a change in the sympathetic-parasympathetic balance, in that the relative sympathetic tone increases along with a decrease in parasympathetic tone. A relationship between changes in $\mathrm{VO}_{2}$ max and HRV alterations during acute hypobaric hypoxia has also been observed, with a decrease in the power of the high (HF) and low frequency (LF) bands and an increase in the LF/HF ratio. ${ }^{15,16}$ Moreover, recent studies on acute mountain sickness (AMS) showed that the predomination of sympathetic activity during high altitude exposure may reflect varying capacity of acute hypobaric hypoxia adaptation ${ }^{17,18}$ and that parameters like HRV could enhance the predictability of AMS susceptibility. ${ }^{18}$ A similar behaviour for cardiorespiratory parameters has also been described for acute simulated altitude exposure. ${ }^{19,20}$ Simulated altitude systems are now more frequently used than "real" high altitude exposure. In this sense there are two types of simulated altitude exposure: hypobaric hypoxia (low pressure chambers) and normobaric hypoxia (hypoxic gas mixtures). Commercially available hypoxic tents (normobaric hypoxia) are now widely used as a complementary tool to conventional training methods, due their low cost and easy use, instead of the hypobaric chambers originally developed to simulate high altitude exposure.

In order to gain a better understanding of the changes and relationships between HRV and cardiorespiratory parameters on simulated high altitude exposure, we conducted a study in two distinct simulated altitude systems: a hypobaric chamber and a hypoxic tent. The main objective was to compare the possible different behaviour of HRV in normoxic and such hypoxic conditions and to determine if HRV could 
be a complementary tool in predicting individual hypoxia tolerance in addition to the results observed by the traditional approach of monitoring arterial oxygen saturation and cardiorespiratory parameters.

\section{Methods}

\section{Subjects}

Seven healthy young men aged $22.7 \pm 5.8$ years (mean \pm SD), weighing $71.7 \pm 5.0 \mathrm{~kg}$ and $179 \pm 7.0 \mathrm{~cm}$ tall, voluntarily participated in this study. Five of them were well-trained subjects, whereas the other two were recreational athletes. None of them were previously acclimatized to altitude. They were submitted twice to a hypoxia tolerance test. The first acute exposure to simulated altitude was performed in a hypobaric chamber; and the second exposure, in a hypoxic tent (see the Hypoxia exposure procedure section for details). In both cases they were exposed to a simulated altitude of approximately $3000 \mathrm{~m}$ above sea level under strict medical control and after a medical examination and electrocardiographic recording. The research was conducted with their written consent, and according to the recommendations of the Declaration of Helsinki.

\section{Hypoxia tolerance test}

The tests were done as previously described. ${ }^{21}$ In brief breathing frequency $(B F)$, tidal volume $\left(V_{T}\right)$, respiratory minute volume $\left(V_{E}\right)$, heart rate $(H R)$, arterial oxygen saturation $\left(\mathrm{SpO}_{2}\right)$ were measured in normoxia and at simulated altitude ( $3000 \mathrm{~m}$ above sea level) at rest and during the fifth minute of exercise on a cycloergometer (Monark 825E, Varberg, Sweden) at sub-maximal workload. This sub-maximal workload was individually established as $50 \%$ of predicted maximal oxygen consumption, according to Åstrand tables and taking into account weight, age and sex. According to this, four recordings were necessary to complete the whole hypoxia tolerance test: first, at rest in normoxic conditions; second, at rest in hypoxic conditions; third, exercising at hypoxic conditions; and fourth, exercising at normoxic conditions. At each step the above mentioned ventilatory and cardiovascular parameters were measured and the cardiac and ventilatory responses to hypoxia were calculated and evaluated as described by Richalet and Herry. ${ }^{22}$ Ventilatory exchange was recorded with a respirometer (Ohmeda 5420, Datex-Ohmeda, Louisville, KY, USA); cardiac frequency was recorded with a Polar $\$ 810 \mathrm{i}$, the same cardiotachometer was used to record HRV (Polar Electro Oy, Kempele, Finland); and $\mathrm{SpO}_{2}$ was measured in each subject with a pulse oximeter (PULSOX-7, Minolta, Osaka, Japan).

\section{Hypoxia exposure procedure}

All the subjects were submitted to the same procedure in order to record HRV measurements and the cardiorespiratory parameters under the two hypoxic conditions. All measurements were always first recorded in normoxic conditions at rest. The subjects were then exposed to simulated altitude conditions until reaching $3000 \mathrm{~m}$ above sea level in a hypobaric chamber (HH condition), which was gradually accomplished in $15 \mathrm{~min}$. HRV and cardiorespiratory parameters obtained in resting conditions were recorded after at least $5 \mathrm{~min}$ of stabilization at altitude and the exercise recordings were obtained subsequently after resting registers were completed. The same protocol was repeated one week later, in a normobaric hypoxic tent $(\mathrm{NH}$ condition). $\mathrm{HH}$ exposure was performed in a hypobaric chamber (CHEx-1 Moelco, Terrassa, Spain) at the premises of Futbol Club Barcelona. NH exposure was attained in a hypoxic tent (Hyp 100 Hypoxic generator, Hypoxico Inc., New York, USA) located in the facilities of the Centre d'Alt Rendiment de Sant Cugat del Vallès (Barcelona), where hypoxia is achieved with a oxygen depletion method that equilibrates gas mixture, until the desired altitude is reached.

\section{Heart rate variability}

All HRV recordings were recorded for at least $6 \mathrm{~min}$, in the same place, at the same time of day and in supine position by two different instruments: a specific ECG recorder (Omegawave Sport Technology System, Portland, OR, USA) and a model of cardiotachometer able to record R-R signals (S810i, Polar Electro Oy, Kempele, Finland). This allowed us to check linearity between these two systems. ${ }^{23}$ Recordings were transferred via infrared port to a specific data processing program ${ }^{24}$ (Polar Precision ${ }^{24}$ Performance Software v.4.03.050, Polar Electro Oy, Kempele, Finland). Once viewed on the notebook screen, the data were filtered to remove any interference. Filtering was achieved with the above software tools on the base of "moderate" filter power with a minimum protection area of 6 beats per min. Data referring to RR interval time $(\mathrm{ms})$ were then exported to an Excel (Microsoft ${ }^{\circledR}$ ) file. Beginning from the first minute of recording, 300 beat-to-beat intervals were selected and stored as text format files to be processed later by means of HRV Analysis Software $1.1,{ }^{25}$ in order to analyze HRV. We evaluated the variations of HRV by time and frequency domain methods. ${ }^{26}$ In the time domain methods, we analyzed the following statistical measurements: RMSSD, expressed in ms, which is the square root of the mean squared differences of successive R-R intervals; and pNN50, expressed in percentage, which is the proportion of the number of interval differences of successive intervals greater than $50 \mathrm{~ms}$. Also in the time domain methods, we used the geometrical nonlinear Poincaré plot analysis with the ellipse fitting procedure. This plot consists of a diagram of the correlation between successive RR intervals, i.e. the plot of $R R_{j+1}$ as a function of $R R_{j}$. The ellipse is oriented according to the line-of-identity $\left(R R_{j}=R R_{j+1}\right)$. The transversal diameter of the ellipse characterizes the standard deviation from the points perpendicular to the line-of-identity (SD1) and describes the short-term variability of heart frequency, whilst the standard deviation along the line-of-identity (SD2) describes the long-term variability. In the frequency domain methods, we analyzed the areas of the spectral peaks of very low frequency (VLF), low frequency (LF) and high frequency (HF) components in percentage (VLF\%, LF\% and $\mathrm{HF} \%$ ) and normalized units (nu), LFnorm and HFnorm. The LF/HF ratio for analysis of the sympathetic-parasympathetic balance was also calculated. 


\section{Statistics}

Descriptive statistics, the non-parametric comparison test and the correlation (Spearman) analysis test were carried out with GraphPad Prism 4 (GraphPad Software, La Jolla, CA, USA), and SigmaPlot 11 (Systat Software, San Jose, CA, USA) software packages. Unless otherwise indicated, data are expressed as mean values $\pm 95 \%$ confidence interval. Statistical significance was assumed for $P<0.05$.

\section{Results}

Table 1 shows the values obtained in the hypoxia tolerance test performed with both artificial hypoxia systems. Under resting conditions, the only parameter that significantly changed was $\mathrm{SpO}_{2}$, which diminished in both $\mathrm{HH}$ (6.2\% decrease) and $\mathrm{NH}$ (7.9\% decrease) from normoxic values. Exercise in $\mathrm{HH}$ elicited a significant $10 \%$ decrease in $\mathrm{SpO}_{2}$ and a $27 \%$ increase in $V_{\mathrm{E}}$ when compared to normoxic exercise. Similar changes were observed in the same parameters for exercising individuals at $\mathrm{NH}$ conditions, which were accompanied by a significant increase in HR. The other respiratory parameters $\left(V_{\mathrm{T}}\right.$ and $\left.\mathrm{BF}\right)$ also showed higher values in both hypoxic conditions during exercise, although the differences were not statistically significant $(P>0.05)$. All subjects studied showed adequate tolerance to hypoxia both in the hypobaric chamber $(\mathrm{HH})$ and inside the hypoxic tent $(\mathrm{NH})$, as indicated by their hypoxic cardiac and ventilatory responses during exercise, which matched the normal threshold values according to Richalet and Herry. ${ }^{22}$

Table 2 shows the time and frequency domain measurements of HRV in normoxic and the two hypoxic conditions. Significant changes from normoxia were found only under $\mathrm{HH}$ conditions and in the indices $\mathrm{HF} \%, \mathrm{LF} \%$, LFnorm and $\mathrm{LF} / \mathrm{HF}$ ratio. No statistically significant changes between normoxia and $\mathrm{NH}$ conditions were seen. To check the usefulness of HRV as a tool for predicting hypoxia tolerance, we analyzed the relationship between HRV indices under normoxic conditions and the response of cardiovascular parameters under acute hypoxia exposure. A statistically significant correlation $(r=0.808, P<0.05)$ between LF\% in normoxia and $\mathrm{SpO}_{2}$ in exercise at $\mathrm{HH}$ (Fig. $1 \mathrm{~A}$ ) and an inverse correlation $(r=-0.636, P=0.125)$ between $\mathrm{HF} \%$ and $\mathrm{SpO}_{2}$ under the same conditions (Fig. 1B) were found. The variation of $\mathrm{SpO}_{2}$ between hypoxic and normoxic conditions, as measured at rest and exercise (a parameter generally accepted as a good indicator for hypoxia tolerance), did not correlate with any HRV index. $V_{E}$ during exercise in $\mathrm{HH}$ was not related to HRV markers under normoxia. Similarly, no correlations were found between HRV indices and the hypoxia tolerance test variables measured in $\mathrm{NH}$ conditions. To validate the consistency of the correlated parameters of HRV in the different situations, we studied the relationship of LF\%, HF\% and LF/HF ratio under normoxic and hypoxic conditions. Fig. 2 shows the correlations found under $\mathrm{HH}$ conditions. Significant correlation was evident in HF\% $(r=0.809, P<0.05)$ and LF/HF ratio $(r=0.994, P<0.001)$ and a lower correlation was found for LF\% $(r=0.741$, $P<0.057)$.

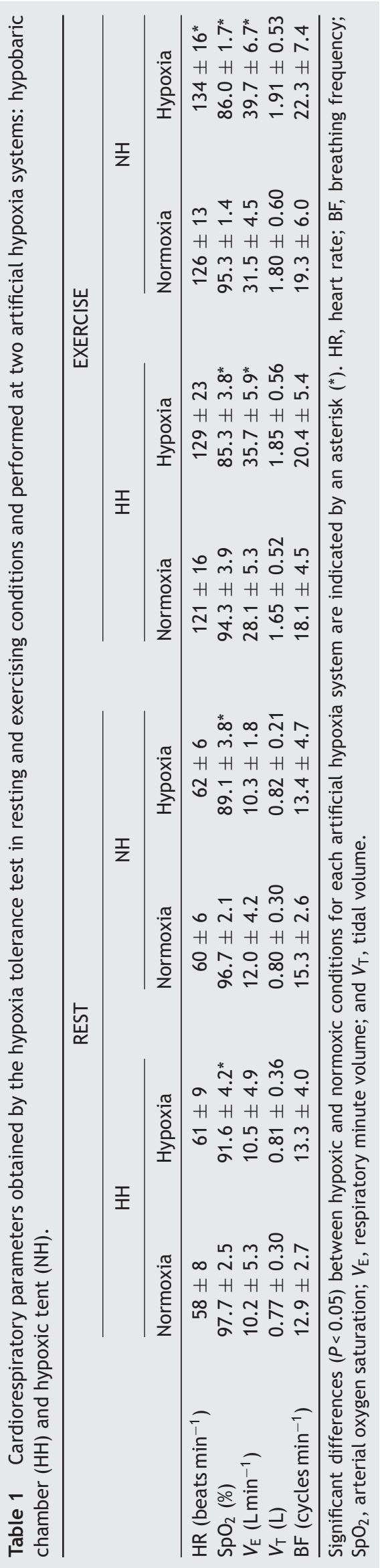



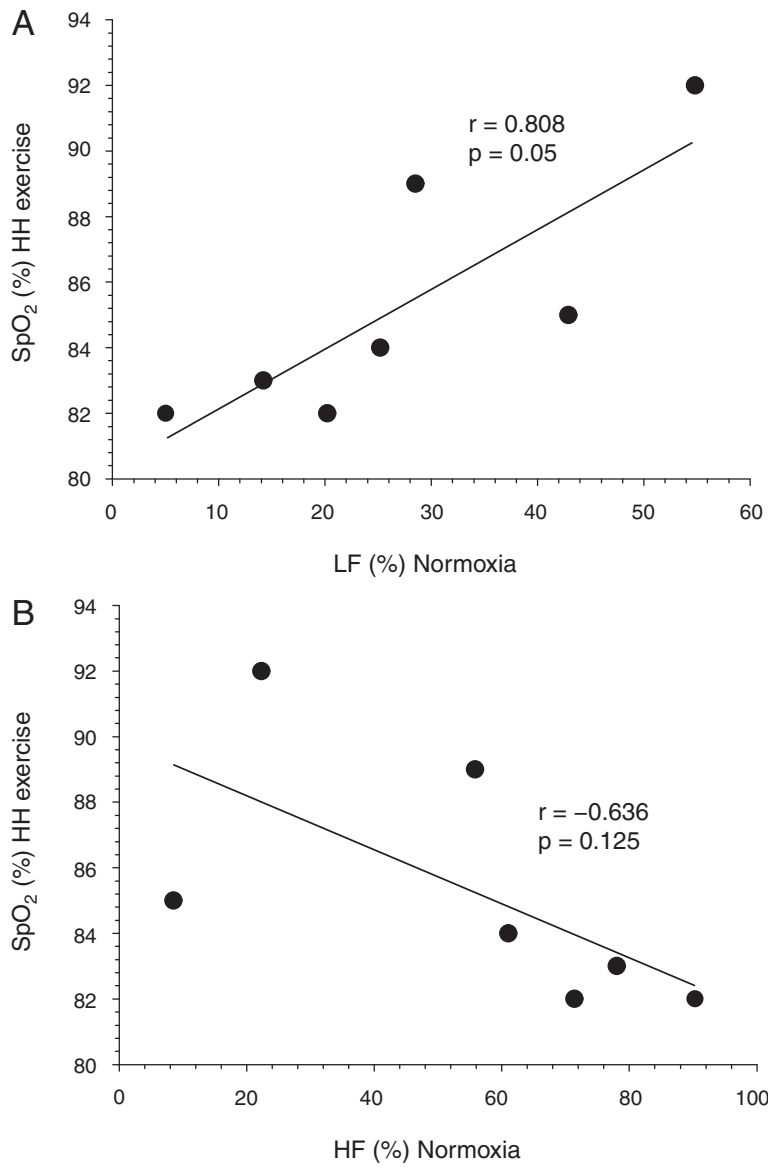

Figure 1 Correlation plots between $\mathrm{LF} \%$ and $\mathrm{HF}^{2}$ and $\mathrm{SpO}_{2}$ in exercise under $\mathrm{HH}$ conditions.

\section{Discussion}

Two major findings are reported in this study: the unexpected differences in the behaviour of some cardiorespiratory and HRV parameters between the two artificial hypoxia systems used; and the correlation between some $\mathrm{HRV}$ measurements in normoxia to $\mathrm{SpO}_{2}$ in exercise at $\mathrm{HH}$. This study has two constraints: first a relatively low number of subjects studied $(n=7)$, although individual characteristics were quite homogeneous, and second the analysis of $\mathrm{HRV}$ is not only influenced by physiological components but also, and at a variable extent, by some psycho-emotional factors. ${ }^{27-29}$

\section{Differences in cardiorespiratory and HRV parameters after hypobaric and normobaric hypoxia exposure}

$\mathrm{SpO}_{2}$ at rest diminished more strongly with exposure to $\mathrm{NH}$ than to $\mathrm{HH}$, and $V_{\mathrm{E}}$ was higher in $\mathrm{NH}$ at exercise than under $\mathrm{HH}$ conditions (Table 1). These differences are due to two main factors. First, there is a slight reduction in air density under hypobaric conditions that justifies a higher ventilation rate for the same work load of the respiratory muscles. Second, as a consequence of the different gas inflow rates into each hypoxic system, a different gas composition (mainly concerning relative humidity and carbon dioxide accumulation) in the two hypoxic conditions can be assumed, leading to a relatively more hypercapnic situation in the hypoxic tent than the hypobaric chamber, as discussed below. Unfortunately, an accurate measurement of gas composition in the hypoxic tent, in order to corroborate this hypothesis, was not made during the experimental performance. Afterwards, before all data were processed, the physical arrangement of normobaric hypoxia system was changed, making impossible to check it in the original conditions.

Table 2 Time and frequency domain measures of HRV in normoxic and the two hypoxic conditions: hypobaric hypoxia in the hypoxic chamber $(\mathrm{HH})$ and normobaric hypoxia in the hypoxic tent $(\mathrm{NH})$.

\begin{tabular}{|c|c|c|c|c|}
\hline & \multicolumn{2}{|c|}{$\mathrm{HH}$} & \multicolumn{2}{|c|}{$\mathrm{NH}$} \\
\hline & Normoxia & Hypoxia & Normoxia & Hypoxia \\
\hline VLF (\%) & $17.4 \pm 15.0$ & $26.2 \pm 15.9$ & $21.4 \pm 11.2$ & $23.7 \pm 9.7$ \\
\hline LF (\%) & $27.3 \pm 17.0$ & $34.4 \pm 14.6$ & $36.9 \pm 15.2$ & $37.8 \pm 12.2$ \\
\hline HF (\%) & $55.3 \pm 29.8$ & $39.4 \pm 22.3^{*}$ & $41.7 \pm 20.7$ & $38.6 \pm 18.0$ \\
\hline LF (nu) & $37.1 \pm 29.1$ & $49.1 \pm 26.0^{*}$ & $48.5 \pm 22.1$ & $50.5 \pm 17.6$ \\
\hline HF (nu) & $62.9 \pm 29.1$ & $50.6 \pm 25.5^{*}$ & $51.5 \pm 22.1$ & $49.5 \pm 17.6$ \\
\hline $\mathrm{LF} / \mathrm{HF}$ & $1.27 \pm 1.84$ & $1.96 \pm 2.6^{*}$ & $1.34 \pm 1.12$ & $1.28 \pm 0.92$ \\
\hline RMSSD (ms) & $55.4 \pm 29.3$ & $54.9 \pm 26.6$ & $56.2 \pm 25.6$ & $47.9 \pm 23.7$ \\
\hline pNN50 (\%) & $35.8 \pm 26.1$ & $32.5 \pm 22.1$ & $31.7 \pm 21.6$ & $27.2 \pm 20.0$ \\
\hline SD1 (ms) & $39.5 \pm 20.8$ & $39.2 \pm 18.8$ & $40.1 \pm 18.2$ & $34.2 \pm 16.9$ \\
\hline SD2 (ms) & $70.4 \pm 28.5$ & $90.4 \pm 34.8$ & $89.9 \pm 34.2$ & $66.6 \pm 23.2$ \\
\hline SD1/SD2 & $0.59 \pm 0.25$ & $0.44 \pm 0.13$ & $0.45 \pm 0.16$ & $0.50 \pm 0.11$ \\
\hline
\end{tabular}

RMSSD, square root of the mean squared differences of successive normal-to-normal intervals; pNN50, proportion of the number of interval differences of successive intervals greater than $50 \mathrm{~ms}$; SD1, standard deviation of the points perpendicular to the line-ofidentity in the Poincaré plot; SD2, standard deviation of the points along the line-of-identity in the Poincaré plot. The areas of the spectral peaks of very low frequency (VLF), low frequency (LF) and high frequency (HF) components are expressed in percentage (\%) and normalized units (nu). Significant differences $(P<0.05)$ between hypoxic and normoxic conditions for each artificial hypoxia system are indicated by an asterisk (*). 

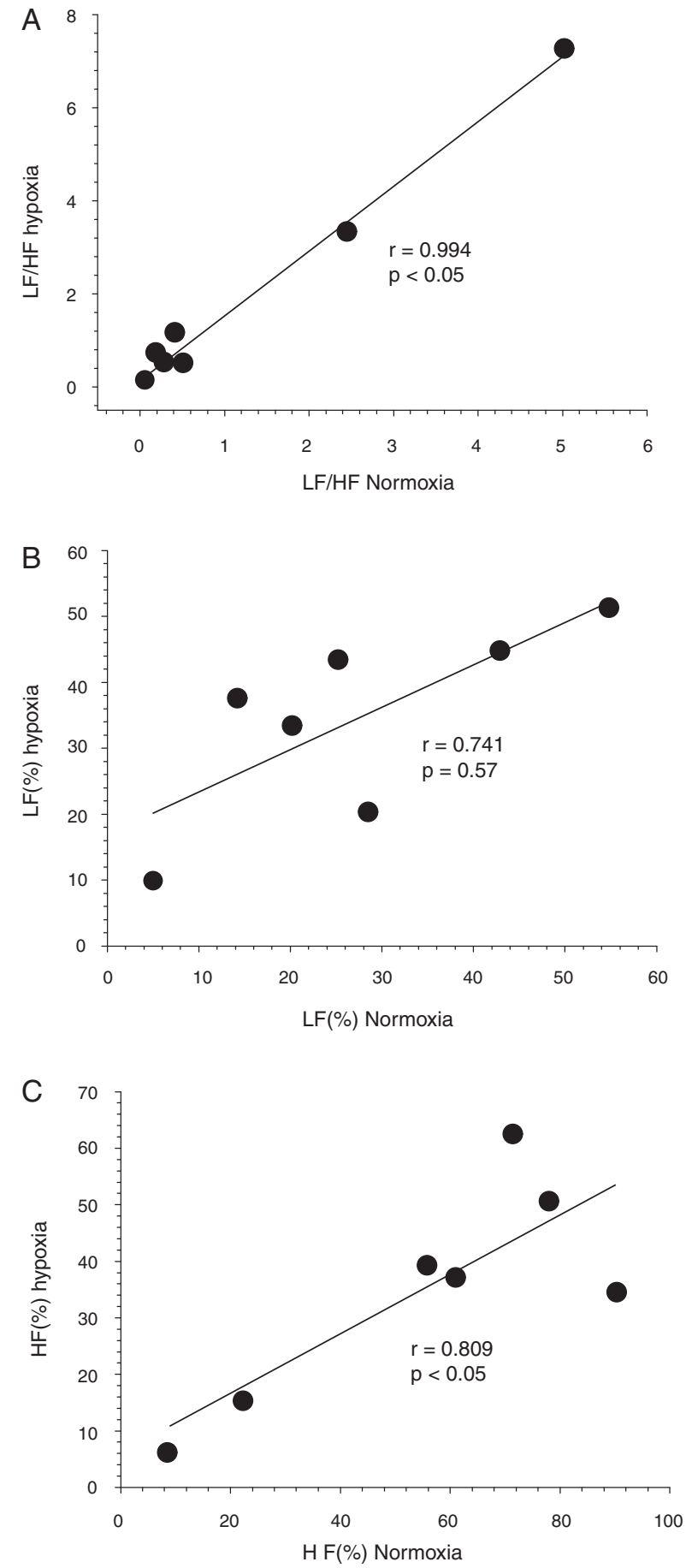

Figure 2 Correlation between normoxia and hypobaric hypoxia conditions for the parameters: LF/HF ratio (A), LF\% (B) and $\mathrm{HF} \%(\mathrm{C})$ in normoxia and $\mathrm{HH}$ condition.

Although we did not measure it, environmental $\mathrm{pCO}_{2}$ could have been higher in $\mathrm{NH}$ than in $\mathrm{HH}$. The difference may have been determined by the geometrical designs and fresh air renewal rates of the two hypoxic systems used, since the hypoxic tent has almost half the total volume of the hypobaric chamber $\left(8 \mathrm{~m}^{3}\right.$ versus $\left.15 \mathrm{~m}^{3}\right)$. Moreover, if gas flow is considered according to the technical data provided by the manufacturers, the difference is even higher: the hypoxic system attached to the tent supplies about $6-7 \mathrm{~m}^{3}$ of gas mixture per hour, whereas the two vacuum pumps of the hypobaric chamber, working simultaneously, extract air at about $300 \mathrm{~m}^{3}$ per hour.

Many authors have described a rise in the sympathetic tone or a vagal withdrawal in response to acute exposure to hypoxia at rest. ${ }^{17,19,29-31}$ The data obtained in our study also reflected these responses by means of a rise in LFnorm and LF/HF ratio and a decrease in $\mathrm{HF} \%$ and $\mathrm{HFnorm}$ under $\mathrm{HH}$ exposure (Table 2). Remarkably, these changes were not observed under NH exposure (Table 2), even though both altitude systems caused a significant decrease in $\mathrm{SpO}_{2}$ when compared to normoxic values (Table 1). The absence of changes in HRV at $\mathrm{NH}$ conditions at rest confirms previous findings, ${ }^{32}$ reporting no changes at a simulated altitude of $3500 \mathrm{~m}$, but contrasts with another recent study describing changes in HF power at $4800 \mathrm{~m}$ above sea level. ${ }^{19}$ The level of simulated altitude exposure could be an important factor affecting these differences, since in NH exposure a threshold of around $10 \% \mathrm{O}_{2}$ (the subjects in our study were submitted to an equivalent of $14 \% \mathrm{O}_{2}$ ) is considered necessary to achieve discernible modifications of muscle sympathetic nerve activity, ${ }^{33}$ a parameter that correlates closely with some HRV indices. ${ }^{34}$ Apart from these differences in HRV, another finding showed discordance between the two simulated altitude systems used in this study: the correlation between the areas of the spectral peaks (LF\%, $\mathrm{HF} \%$ and the LF/HF ratio) in normoxia and in $\mathrm{HH}$ (Fig. 2) was not observed when the subjects were submitted to $\mathrm{NH}$, demonstrating that subjects with higher sympathetic modulation in normoxia maintained this condition during $\mathrm{HH}$, but not during $\mathrm{NH}$ exposure. These two findings showed different behaviour of HRV in the two hypoxic conditions, which supports the hypothesis that, for the same simulated altitude of $3000 \mathrm{~m}$ a.s.l., $\mathrm{NH}$ and $\mathrm{HH}$ are not equal stimuli to the cardiovascular and respiratory systems, and probably affects also in a different way the psychoemotional status and the behaviour of the subjects. Our findings on this different HRV behaviour between the two simulated altitude systems corroborate previous studies that reported different cardioventilatory responses between $\mathrm{HH}$ and $\mathrm{NH}$ exposures. ${ }^{35-37}$ In addition, since HRV is also sensitive to psycho-emotional factors, ${ }^{27-29,38}$ differences in comfort and environmental conditions between $\mathrm{HH}$ and $\mathrm{NH}$ may have affected the differences here reported.

\section{Correlation between HRV measurements in normoxia and $\mathrm{SpO}_{2}$ in exercise at $\mathrm{HH}$}

The reduced partial pressure of oxygen at altitude causes the arterial oxygen saturation in the blood to decrease. ${ }^{39}$ Burstcher et al., ${ }^{18}$ after reviewing the PubMed database from 1976 to 2007, concluded that arterial oxygen saturation values, determined 20-30 min after exposure to hypoxia equivalent to $2300-4200 \mathrm{~m}$, were the most useful predictors of AMS susceptibility. Furthermore, exercise accelerates and increases the severity of AMS, which is associated with the greater arterial hypoxemia that takes place during exercise at high altitude. ${ }^{40}$ In addition, acute hypoxia is a potent activator of the sympathetic nervous system in at least two ways. It causes relaxation of the vascular smooth muscle of the systemic circulation, which leads to hypotension 
that activates baroreceptor mediation in order to maintain homeostasis. The other way is through stimulation of pulmonary arterial baroreceptors in order to reduce the pulmonary hypertension elicited by the hypoxic stimulus. ${ }^{41}$ As mentioned above, this sympathetic activation is reflected in changes in some HRV parameters under $\mathrm{HH}$. An inverse relationship between sympathetic nerve activity and arterial $\mathrm{SpO}_{2}$ in subjects with and without history of high altitude pulmonary oedema has been observed. ${ }^{42}$ Sympathetic nerve activity was also directly related to pulmonary artery pressure. Even though this study was conducted under different conditions (after 24-36h of staying at $4559 \mathrm{~m}$ above sea level), the relationship between sympathetic activity and $\mathrm{SpO}_{2}$ remains important. The different slope of this relationship can be justified by the time course of events: on reaching high altitude, a high sympathetic tone may be beneficial in order to activate homeostatic mechanisms. As the subject acclimatizes to the hypoxic environment and other physiological adjustments are on the go, a high sympathetic tone is no longer beneficial, and it needs to decline to conserve a physiological response and to maintain adequate $\mathrm{SpO}_{2}$.

Here we report a significant correlation between sympathetic and vagal modulation in normoxia and $\mathrm{SpO}_{2}$ at exercise in $\mathrm{HH}$ (Fig. 1). Individuals with higher sympathetic modulation (LF\%) in normoxia had higher $\mathrm{SpO}_{2}$ at exercise in $\mathrm{HH}$ (Fig. $1 \mathrm{~A})$ and individuals with higher vagal modulation $(\mathrm{HF} \%)$ in normoxia showed lower $\mathrm{SpO}_{2}$ in exercise at $\mathrm{HH}$ (Fig. 1B). Since correlations in $\mathrm{LH} \%, \mathrm{HF} \%$ and $\mathrm{LF} / \mathrm{HF}$ ratio between normoxia and $\mathrm{HH}$ conditions were also found (Fig. 2), we hypothesize that the evaluation of HRV in normoxia is a good predictor of the capacity of each subject to altitude acclimation. Some recent studies support this idea. A positive correlation between $\mathrm{SpO}_{2}$ and $\mathrm{LF}$ power at high altitude, in unacclimatized subjects in rapid ascent to $3456 \mathrm{~m}$ has been reported ${ }^{43}$ and Chen et al. ${ }^{17}$ found that, after a rapid ascent to $3180 \mathrm{~m}$, the unacclimatized healthy subjects that suffered AMS had more discordant changes in their HRV variables at high altitude than those subjects that did not show AMS. These findings indicate that the study of HRV could be a useful tool for evaluating the varying capacity of acute hypobaric hypoxia adaptation.

There are broad differences between individuals in the several physiological changes that occur in people when they ascend to high altitude, revealing individual differences in the tolerance to hypoxia and/or the ability to acclimatize. ${ }^{39,18}$ Unfortunately, current research does not offer any test for ascertaining individual tolerance to hypoxia induced by altitude exposure that could be widely and easily used. The final objectives of the test should be to predict the potential capacity of each subject for altitude acclimation and to develop physical exercise under hypoxic conditions, in order to select people for altitude work according to risk criteria and to take the appropriate preventive measures. For optimal and wide application, this test should be based on the non-invasive recording of physiological changes induced by acute hypobaric exposure. We believe that the correlation that we found between HRV measured in normoxia and $\mathrm{SpO}_{2}$ measured in $\mathrm{HH}$ opens up the possibility of using this tool in the prediction of tolerance to acute altitude exposure.
On the other hand, the use of hypoxia exposure as a complementary tool for athlete training must be carefully evaluated. According to our results, hypobaric and normobaric systems are different stimuli, at least as usually applied, probably eliciting a higher degree of variability in physiological responses to altitude acclimation in humans.

\section{Funding}

This study was covered in part by grant 08/UPB10/06 from Consejo Superior de Deportes. Carla Basualto-Alarcón's stay in Barcelona was covered by a grant through the HAPPOM (High Altitude Physiology and Pathophysiology: from Organism to Molecule) Project II-0379-FCD of the European Commission's ALFA Programme.

Claus Behn acknowledges support from FONDECYT, Chile (Proj. Nr. 1100161).

\section{Conflicts of interest}

The authors have no conflicts of interest to declare.

\section{Acknowledgement}

The authors are grateful to Mr. Robin Rycroft (SAL-UB) for his help in editing the manuscript.

\section{References}

1. Grant S, MacLeod N, Kay JW, Watt M, Patel S, Paterson A, et al. Sea level and acute responses to hypoxia: do they predict physiological responses and acute mountain sickness at altitude? $\mathrm{Br}$ J Sports Med. 2002;36:141-6.

2. Calbet JAL, Radegran G, Boushel R, Sondergaard H, Saltin $B$, Wagner PD. Effect of blood haemoglobin concentration on $\mathrm{V}\left(\mathrm{O}_{2}, \max \right)$ and cardiovascular function in lowlanders acclimatised to $5260 \mathrm{~m}$. J Physiol (Lond). 2002;545:715-28.

3. Basnyat B, Murdoch DR. High-altitude illness. Lancet. 2003;361:1967-74.

4. Calbet JAL, Boushel R, Radegran G, Sondergaard $H$, Wagner PD, Saltin B. Determinants of maximal oxygen uptake in severe acute hypoxia. Am J Physiol. 2003;284:R291-303.

5. Calbet JAL, Boushel R, Radegran G, Sondergaard H, Wagner $\mathrm{PD}$, Saltin $\mathrm{B}$. Why is $\mathrm{VO}_{2}$ max after altitude acclimatization still reduced despite normalization of arterial $\mathrm{O}_{2}$ content? Am J Physiol. 2003;284:R304-16.

6. Cerretelli P. Limiting factors to oxygen transport on Mount Everest. J Appl Physiol. 1976;40:658-67.

7. Bernardi L, Passino C, Spadacini G, Calciati A, Robergs R, Greene $\mathrm{R}$, et al. Cardiovascular autonomic modulation and activity of carotid baroreceptors at altitude. Clin Sci. 1998;95:565-73.

8. Magalhaes J, Ascensao A, Viscor G, Soares J, Oliveira J, Marques $F$, et al. Oxidative stress in humans during and after 4 hours of hypoxia at a simulated altitude of $5500 \mathrm{~m}$. Aviat Space Environ Med. 2004;75:16-22.

9. Rapino C, Bianchi G, Giulio CD, Centurione L, Cacchio $M$, Antonucci A, et al. HIF- $1 \alpha$ cytoplasmic accumulation is associated with cell death in old rat cerebral cortex exposed to intermittent hypoxia. Aging Cell. 2005;4:177-85.

10. Sztajzel J. Heart rate variability: a noninvasive electrocardiographic method to measure the autonomic nervous system. Swiss Med Wkly. 2004;134:514-22. 
11. Marocolo M, Nadal J, Benchimol-Barbosa PR. The effect of an aerobic training program on the electrical remodeling of the heart: high-frequency components of the signal-averaged electrocardiogram are predictors of the maximal aerobic power. Braz J Med Biol Res. 2007;40:199-208.

12. Pluim BM, Swenne CA, Zwinderman AH, Maan AC, van der Laarse $A$, Doornbos J, et al. Correlation of heart rate variability with cardiac functional and metabolic variables in cyclists with training induced left ventricular hypertrophy. Heart. 1999;81:612-7.

13. Cornolo J, Mollard P, Brugniaux JV, Robach P, Richalet JP. Autonomic control of the cardiovascular system during acclimatization to high altitude: effects of sildenafil. J Appl Physiol. 2004;97:935-40.

14. Schmitt L, Fouillot JP, Millet GP, Robach P, Nicolet G, Brugniaux $\mathrm{J}$, et al. Altitude, heart rate variability and aerobic capacities. Int J Sports Med. 2008;29:300-6.

15. Melin A, Fauchier L, Dubuis E, Obert P, Bonnet P. Heart rate variability in rats acclimatized to high altitude. High Alt Med Biol. 2003;4:375-87.

16. Hainsworth R, Drinkhill MJ. Cardiovascular adjustments for life at high altitude. Respir Physiol Neurobiol. 2007;158:204-11.

17. Chen YC, Lin FC, Shiao GM, Chang SC. Effect of rapid ascent to high altitude on autonomic cardiovascular modulation. Am J Med Sci. 2008;336:248-53.

18. Burtscher M, Szubski C, Faulhaber M. Prediction of the susceptibility to AMS in simulated altitude. Sleep Breath. 2008;12:103-8.

19. Buchheit M, Richard R, Doutreleau S, Lonsdorfer-Wolf E, Brandenberger $\mathrm{G}$, Simon $\mathrm{C}$. Effect of acute hypoxia on heart rate variability at rest and during exercise. Int J Sports Med. 2004;25:264-9.

20. Povea C, Schmitt L, Brugniaux J, Nicolet G, Richalet J, Fouillot J. Effects of intermittent hypoxia on heart rate variability during rest and exercise. High Alt Med Biol. 2005;6:215-25.

21. Ricart $A$, Casas $H$, Casas $M$, Pagès $T$, Palacios $L$, Rama R, et al. Acclimatization near home? Early respiratory changes after short-term intermittent exposure to simulated altitude. Wilderness Environ Med. 2000;11:84-8.

22. Richalet JP, Herry JP. Médecine de l'alpinisme et des sports de montagne. 4th ed. Paris: Masson; 2006.

23. Parrado E, Garcia MA, Ramos J, Cervantes JC, Rodas G, Capdevila L. Comparison of Omega Wave System and Polar S810i to detect R-R intervals at rest. Int J Sports Med. 2010;31:336-41.

24. Polar Precision Performance SW. 2007;4.03.050.

25. Karjalainen PA. HRV Anal Softw. 2005;1:SP1.

26. Electrophysiology, Task Force of the European Society of Cardiology the North American Society of Pacing. Heart rate variability: standards of measurement, physiological interpretation, and clinical use. Circulation. 1996;93:1043-65.

27. Cervantes Blasquez JC, Rodas Font G, Capdevila Ortis L. Heart-rate variability and precompetitive anxiety in swimmers. Psicothema. 2009;21:531-6.
28. Ruiz-Padial E, Sollers 3rd JJ, Vila J, Thayer JF. The rhythm of the heart in the blink of an eye: emotion-modulated startle magnitude covaries with heart rate variability. Psychophysiology. 2003;40:306-13.

29. Bernardi L, Sleight P, Bandinelli G, Cencetti S, Fattorini L, Wdowczyc-Szulc J, et al. Effect of rosary prayer and yoga mantras on autonomic cardiovascular rhythms: comparative study. Br Med J. 2001;323:1446-9.

30. Fukuda-Matsuda E, Yamada M, Tanobe K, Saito S. Peripheral circulation monitored by surface temperature and autonomic nervous function in hypobaric hypoxic environment: effects of submaximal exercise. Int J Environ Health Res. 2007;17:53-60.

31. Zupet P, Princi T, Finderle Z. Effect of hypobaric hypoxia on heart rate variability during exercise: a pilot field study. Eur J Appl Physiol. 2009;107:345-50.

32. Yamamoto Y, Hoshikawa Y, Miyashita M. Effects of acute exposure to simulated altitude on heart rate variability during exercise. J Appl Physiol. 1996;81:1223-9.

33. Somers VK, Mark AL, Zavala DC, Abboud FM. Contrasting effects of hypoxia and hypercapnia on ventilation and sympathetic activity in humans. J Appl Physiol. 1989;67:2101-6.

34. Pagani M, Montano N, Porta A, Malliani A, Abboud FM, Birkett C, et al. Relationship between spectral components of cardiovascular variabilities and direct measures of muscle sympathetic nerve activity in humans. Circulation. 1997;95:1441-8.

35. Conkin J, Wessel 3rd JH. Critique of the equivalent air altitude model. Aviat Space Environ Med. 2008;79:975-82.

36. Savourey G, Launay J, Besnard Y, Guinet-Lebreton A, Alonso A, Sauvet F, et al. Normo or hypobaric hypoxic tests: propositions for the determination of the individual susceptibility to altitude illnesses. Eur J Appl Physiol. 2007;100:193-205.

37. Savourey G, Launay JC, Besnard Y, Guinet A, Travers S. Normoand hypobaric hypoxia: are there any physiological differences? Eur J Appl Physiol. 2003;89:122-6.

38. Appelhans BM, Luecken LJ. Heart rate variability as an index of regulated emotional responding. Rev Gen Psychol. 2006;10:229-40.

39. Brundrett G. Sickness at high altitude: a literature review. J R Soc Promot Health. 2002;122:14-20.

40. Roach RC, Maes D, Sandoval D, Robergs RA, Icenogle M, Hinghofer-Szalkay $\mathrm{H}$, et al. Exercise exacerbates acute mountain sickness at simulated high altitude. J Appl Physiol. 2000;88:581-5.

41. Hainsworth R, Drinkhill M, Rivera-Chira $M$. The autonomic nervous system at high altitude. Clin Auton Res. 2007;17:13-9.

42. Duplain $H$, Vollenweider L, Delabays A, Nicod P, Bärtsch P, Scherrer $\mathrm{U}$. Augmented sympathetic activation during short-term hypoxia and high-altitude exposure in subjects susceptible to high-altitude pulmonary edema. Circulation. 1999;99:1713-8.

43. Saito S, Tanobe K, Yamada M, Nishihara F. Relationship between arterial oxygen saturation and heart rate variability at high altitudes. Am J Emerg Med. 2005;23:8-12. 